\title{
КУЛЬТУРНЫЙ ТУРИЗМ НА ПРИМЕРЕ ГРУППОВОГО ТУРА НА ПОЕЗДЕ МОСКВА - НИЦЦА
}

\author{
Дикун Наталья Александровна \\ магистрант \\ Научный руководитель: Маркина Кира Николаевна \\ к.н., доцент \\ кафедры РиСО «Санкт-Петербургский \\ Гуманитарный Университет Профсоюзов»
}

Аннотация: Основная цель этой статьи - показать как можно развивать культурный и социальный туризм на примере групповой поездки на поезде Москва- Ницца (РЖД) для людей 60+.

Актуальность такого тура заключается в том, что он не только поможет нашим соотечественникам познакомиться с достопримечательностями нескольких городов Европы, но и позволит провести параллели между российской и западной культурами. Помимо этого маршрут предполагается построить так, чтобы посетить места, которые некогда были излюбленными именно для путешественников из России. Таким образом, у туристов будет возможность решить несколько задач как познавательного, так и развлекательного характера. Возможность совершить путешествие в комфортабельном вагоне поезда «Москва - Ницца» создаст необходимые условия для приятного времяпровождения без стресса и спешки. А путешествие в группе позволит участникам пообщаться, познакомиться с новыми людьми и завязать дружеские отношения. Предполагается, что этот тур будет реализован для группы людей 60+, т.к. для путешествия по железной дороге необходимо иметь свободное время. Как отмечают специалисты по долголетию, в зрелом возрасте очень важно занимать активную жизненную позицию, оставаться любознательным и открытым для новых знаний и впечатлений, а также сохранять социальные навыки и общаться.

Ключевые слова. Культурный туризм, социальный туризм, Европа, Вена, Больцано, Мерано, Ницца, русская эмиграция, российская культура, западноевропейская культура. 


\section{CULTURAL TOURISM ON THE EXAMPLE OF A GROUP TOUR BY TRAIN MOSCOW-NICE}

Abstract: The main goal of this article is to show how we can develop cultural and social tourism using the example of a group trip on the Moscow-Nice (Russian Railways) train for people $60+$.

The relevance of such a tour lies in the fact that it will not only help our compatriots to get acquainted with the sights of several European cities, but also allow them to draw parallels between Russian and Western cultures. In addition, the route is supposed to be built in such a way as to visit places that were once favorite for travelers from Russia. Thus, tourists will have the opportunity to solve several tasks of both educational and entertainment nature. The opportunity to travel in a comfortable carriage of the Moscow - Nice train will create the necessary conditions for a pleasant pastime without stress and haste. And traveling in a group will allow participants to socialize, meet new people and form friendships. It is assumed that this tour will be implemented for a group of 60+ people, because to travel by rail, you need to have free time. As experts in longevity note, in adulthood it is very important to take an active life position, remain curious and open to new knowledge and impressions, as well as socialize and communicate.

Key words: Cultural tourism, social tourism, Europe, Vienna, Bolzano, Merano, Nice, Russian emigration, Russian culture, Western European culture.

В данной статье рассматриваются проблемы, которые предполагается хотя бы частично решить благодаря организации железнодорожного тура Москва- Ницца (РЖД) для аудитории 60+. Предлагается создать путешествие на базе уже существующего маршрута, который был запущен 23 сентября 2010 года, после почти столетнего перерыва.

Первые поезда из России в Ниццу начали ходить в 1864-м году. Тогда столицей российской империи был Санкт-Петербург, и поезд в Ниццу отправлялся именно оттуда. В 1914-м году, в связи с началом Первой Мировой войны, железнодорожное сообщение по этому направлению прекратилось.

До того времени маршрут был очень популярен, потому что проходил через несколько курортных городов, так любимых россиянами и в наши дни. Самым популярным из них был город Ницца. В XX-м веке он был одним из излюбленных курортов российской аристократии, а в дальнейшем Ницца стала одним из центров русской эмиграции. 
Однако есть еще одна локация, которую поэты называли «Альпийской Ниццей». Это город Мерано (ныне Италия, провинция Больцано). На посещении его и будет сделан акцент в этой работе.

Поезд отправляется от станции “Москва Белорусская", и дорога до Ниццы занимает обычно чуть больше двух дней. Протяженность пути 2917 км. На этом маршруте - 29 остановок. Поезд очень комфортабельный, в каждом купе - по два спальных места. Есть отличный ресторан. Обслуживающий персонал внимателен и профессионален.

Именно в связи с тем, что путешествие - достаточно долгое, этот тур предлагается людям старшего возраста, т.к. они располагают свободным временем и могут себе позволить никуда не спешить. Если молодые и работающие люди предпочитают скорость и практичность, представители зрелого поколения больше оценят комфортабельные условия поезда и спокойную обстановку. Средняя скорость поезда 73 км/ч, поэтому туристы смогут насладиться европейскими пейзажами из окна своего вагона.

В целом путешествие по Европе, которое авторы назвали «По следам российской аристократии», будет длиться 23 дня. В данном маршруте организаторы предусмотрели 2 длительные остановки. На пути в Ниццу путешественники остановятся в Больцано (Италия). Здесь они сойдут с поезда, чтобы остаться на неделю. Далее, со следующим поездом (он ходит раз в неделю) они проследуют в Ниццу. А на обратном пути, после недельного проживания на Лазурном Берегу, туристы посетят Вену (Австрия). Там они тоже пробудут 7 дней, чтобы посетить местные музеи и достопримечательности. Затем они с комфортом вернутся в Россию.

Помимо этого, продукт может быть предложен как летний познавательный тур для школьников средних и старших классов, изучающих немецкий, английский, итальянский и/или французский языки. В этом случае одна половина дня будет посвящена экскурсиям, а вторая половина дня занятиям иностранным языком, а также общением и занятиями на свежем воздухе со сверстниками, проживающими в данном регионе и изучающими русский язык. Таким образом школьники смогу в непринужденной обстановке оттачивать навыки общения на иностранном языке и познавать культуру другой страны. Представляется возможным также организовать этот тур в качестве индивидуального, а не группового, например, как свадебное путешествие для молодоженов. 
Если популярность этого маршрута будет велика, возможно, РЖД решит увеличить количество рейсов. Тогда длительность тура и программу можно будет варьировать в соответствии с потребностями путешественников.

В данной статье не представляется возможным подробно разобрать тур целиком. Более подробно здесь будет описан этап остановки в г.Больцано с посещением г.Мерано - курорта, некогда столь любимого русской аристократией, а в наши дни популярного у обеспеченных россиян.

Поезд прибывает в г.Больцано в субботу утром (отправляется он из Москвы в четверг вечером). Ниже приводится программа тура на неделю.

День 1: «По следам Ötzi - человека, найденного во льдах»

Прибытие на поезде в Больцано, размещение в отеле, легкий обед, экскурсия по городу. В нее включено посещение археологического музея, где хранится мумия «человека, найденного во льдах» [5, с.34].

В 1991 году - 30 лет назад двумя немецкими туристами были случайно найдены во льдах Южного Тироля мумия древнего человека, которому около 5300 лет. Ötzi, как назвали найденного, жил во времена медного века. Эта находка стала одной из важнейших в конце XX века и позволила археологам, антропологам и другим ученым сделать множество открытий о наших далеких предках и развитии жизни и цивилизации на Земле. Сейчас эта мумия хранится в археологическом музее Больцано. Представляется, что те, кто посетил этот город, не могут не взглянуть на научный артефакт такой важности.

Помимо археологического музея, группа посетит центральную площадь (Piazza Walther - Walther Platz), Домский собор, церковь Доминиканцев с уникальными фресками работы учеников школы живописца Джотто [1, с.68]. Гости посетят также средневековый овощной рынок (Piazza delle Erbe Obstplatz) и другие достопримечательности. Далее у гостей будет ужин и свободное время.

День 2: «Иллюстрированный замок Runkelstein»

Завтрак, пешеходная прогулка к замку (по прогулочной дорожке, рекомендуется удобная обувь). Уровень сложности маршрута - легкий, перепад высоты 200 м, дистанция 2,6 км.

По прибытии - экскурсия по замку, который уникален тем, что был построен двумя аристократами в XIII веке, как крепость. Он переходил от одних владельцев к другим, был частично перестроен. При этом, в замке сохранились великолепные фрески в Рыцарском и Гербовом залах, в зале Тристана и Изольды. Одной из наиболее известных является фреска «Круглый стол короля Артура» (рис.1). 


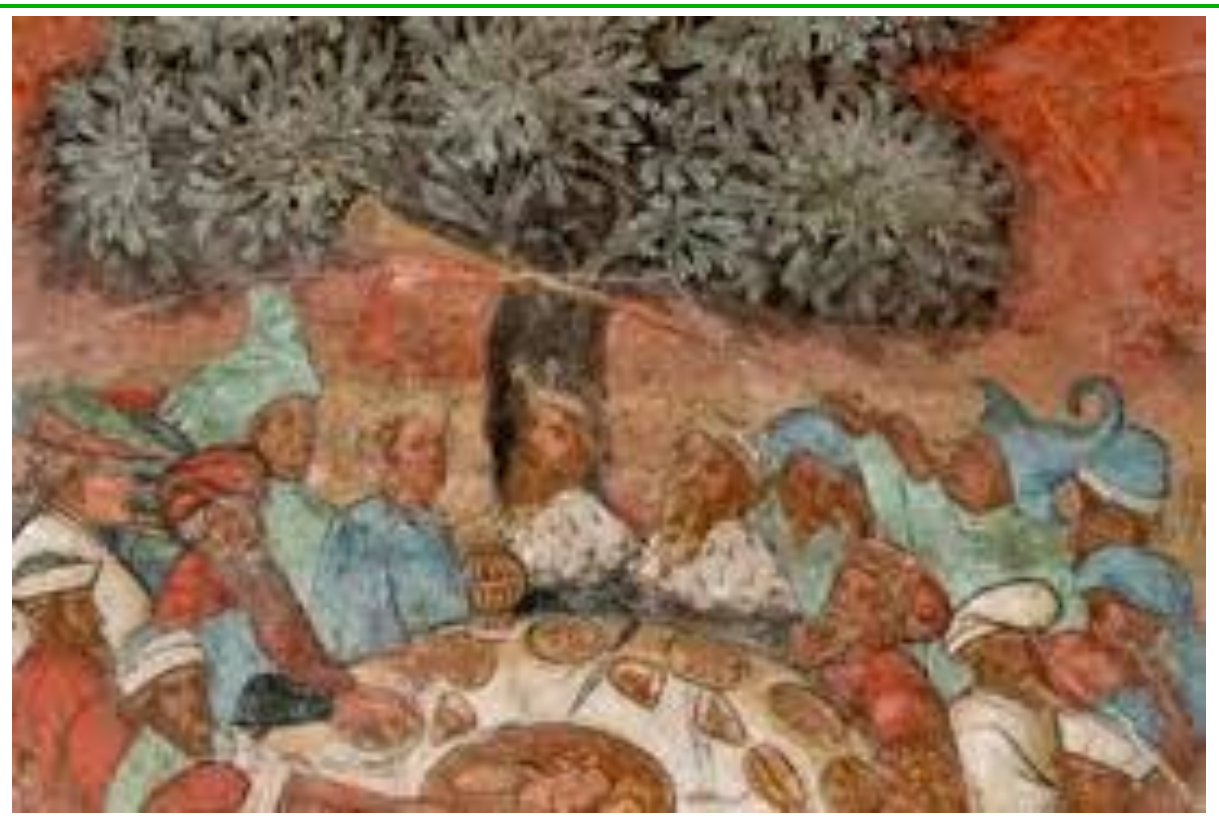

Рис.1. Фреска «Круглый стол короля Артура»

После возвращения в отель и обеда, предполагается свободное время. Для желающих - посещение музея альпинизма в замке «Фирмиан» на автобусе.

День 3: «Жемчужина Альп - Мерано. По следам русской аристократии».

Завтрак, переезд в г.Мерано на электропоезде. Экскурсия по городу с посещением знаменитого Курхауса. Туристы увидят также парк принцессы Елизаветы Баварской (Сисси), старинную пороховую башню, Римский мост, Свято-Никольский православный храм.

Как уже упоминалось, город Мерано (Meran, нем.) которым восхищались художники и поэты, называя его «Жемчужиной Альп», всегда привлекал внимание российской аристократии. Благодаря своему мягкому климату и термальным водам, он стал очень известным. Множество туристов со всей Европы стекалось сюда начиная с конца XIX-го века. Любили Мерано и наши соотечественники. Особенной популярностью пользовался этот курорт у страдавших от туберкулёза. Эта болезнь была нередкой у жителей СанктПетербурга и Москвы. Местный климат хорошо сказывался на здоровье приезжавших. Мерано был не просто местом для лечения, но и модным курортом. Здесь были построены великолепные отели такие как, например, Палас Отель. Был возведён Курхаус ( рис. 2) с богато украшенным павильоном Курсаал, где проводились балы. Там же были обширная библиотека и ресторан с изысканной кухней. 


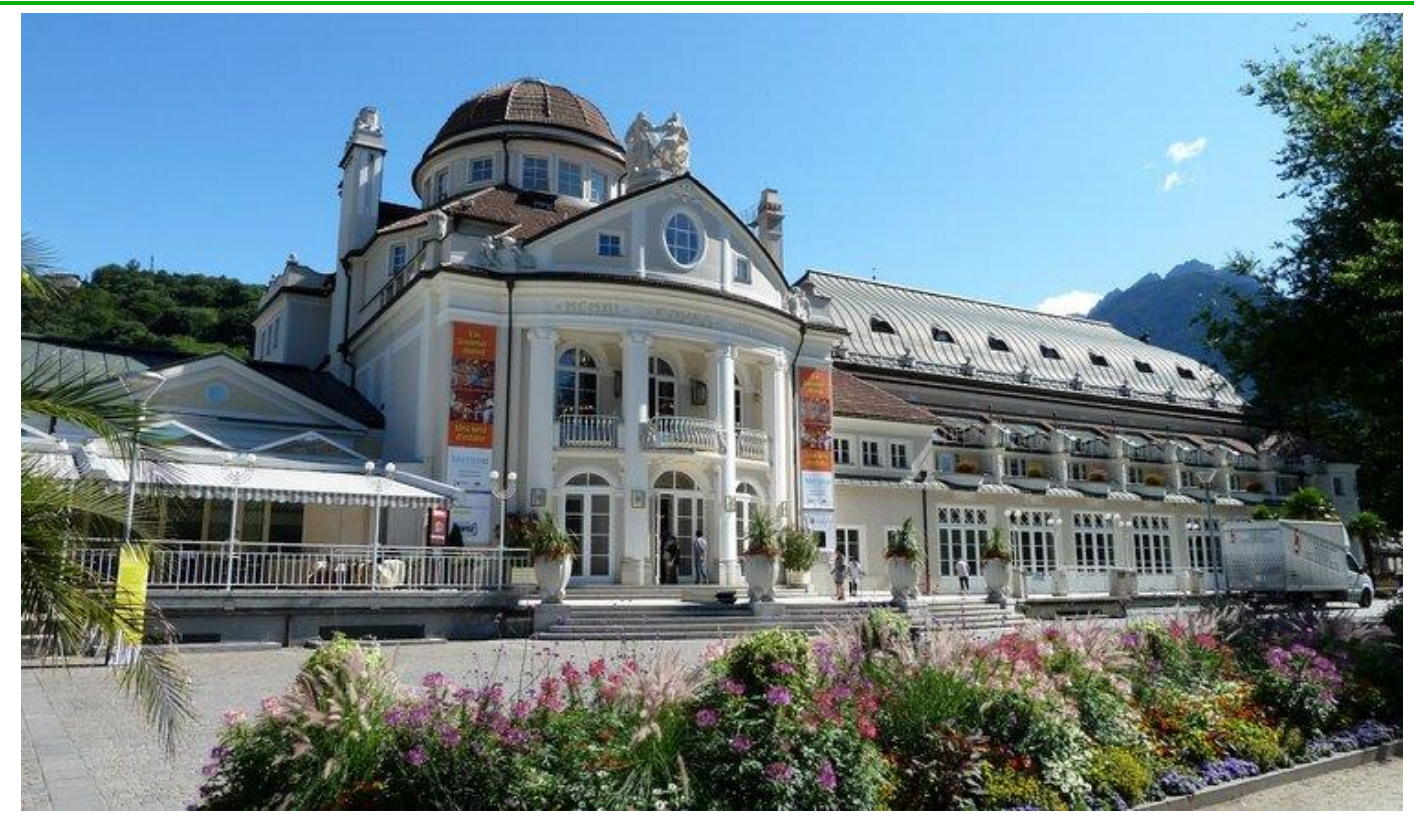

Рис 2. Курхаус, г.Мерано.

Посещение Свято-Никольского православного храма.

Русские, приезжавшие в Меран, чувствовали сильное желание посетить православную церковь. Можем предположить, что для многих пациентов с туберкулёзом, религиозность усиливалась от сознания хрупкости их земного существования. Известна преданность русских православию, к которой добавлялась ностальгия по далёкой Родине, «святой Руси». Все эти причины послужили стимулом, чтобы начать строить русскую церковь в Мерано. Комитет который возглавлял доктор Михаил фон Мессинг, попросил благословения митрополита Исидора Никольского. Связь с Санкт-Петербургом была неслучайной. Как уже говорилось, этот город был столицей Российской империи, и его митрополит председательствовал над всеми русскими церквями за рубежом. Комитет обратился к нему и объявил что многие россияне посещают и живут в Мерано (почти 400 человек в году), и что австрийское правительство уже дало разрешение на строительство православного храма. Как известно, эта территория в то время принадлежала Австро-Венгерской империи.

Не исключено, что протоирей Иоанн Кронштадтский, который был канонизирован в 1988-м году, помог своим попечительством, своим авторитетом, в принятии положительного решения о строительстве церкви. Действительно, знаменитый «батюшка всея Руси» был в числе членов благотворительного комитета. 
9 декабря 1884 года с благословения митрополита Исидора был освящен храм Св.Николая Чудотворца, сначала в помещении, снимаемом в аренду[3, c.86]. Этот святой является одним из наиболее почитаемых в России. Его считают своим покровителем крестьяне, моряки и торговцы.

В Италии большинство русских церквей посвящены святому Николаю: во Флоренции (нижний храм), в Риме, в Бари. Католический собор Мерано тоже назван в честь святого Николауса. Возможно, этот факт повлиял на решение о выборе покровителя русской общиной, так как таким образом наши соотечественники могли бы лучше интегрироваться в местную культурную и религиозную среды.

Великая княгиня Екатерина Михайловна была почётным опекуном храма и подарила 500 гульденов. Русская община собирала деньги на строительство собственной церкви с 1880 года.

Строительство храма стало возможно, благодаря средствам, оставленным в наследство Надеждой Ивановной Бородиной. Эта женщина, дочь влиятельного чиновника из России, посещала Мерано, будучи тяжело больной. Она завещала крупную сумму от своего наследства русской общине г. Мерано для строительства дома для соотечественников, приезжавших сюда на лечение.

Тироль посетили в те годы и другие известные люди. Например, этнограф Алексей Бобринский, а также дочь известного писателя Л.Ф. Достоевская. Она была писательницей и биографом, последние годы жизни провела в Больцано и там похоронена. Жила в Мерано также пианистка и композитор Наталья Правосудович, ученица Шенберга[4, с.154].

Строительство Русского Дома им. Бородиной длилось с 1895-го по 1897й годы. Церковь святого Николая была построена на первом этаже виллы (рис. $3)$. 


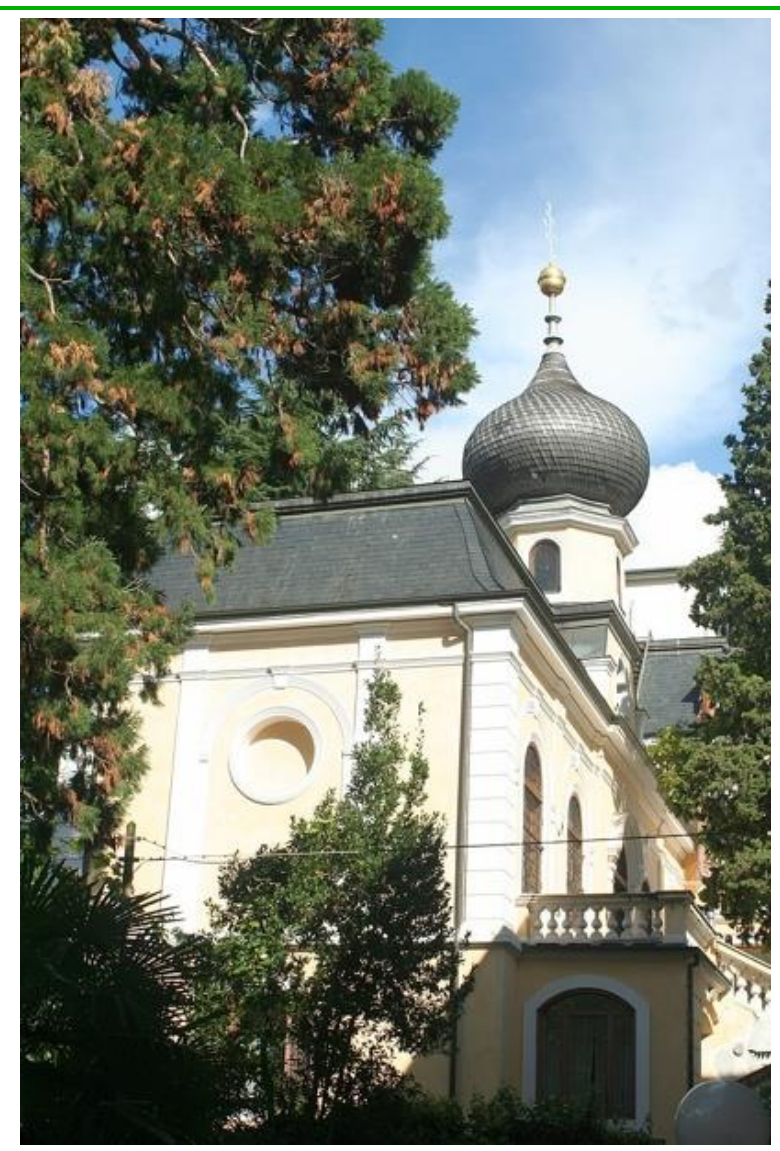

\section{Рис 3. Свято-Никольского православный храм в Мерано.}

Торжественное благословение храма состоялось Зго (15) декабря 1897 г., накануне праздника своего покровителя Святителя Николая. Храм продолжал проводить службы каждую зиму. Его деятельность оборвалась 1914-м году.

В настоящее время храм действует, и в нем служатся литургии три первых воскресенья каждого месяца.

После экскурсии группа может посетить «Терме» г. Мерано, а затем возвратиться в отель в Больцано.

День 4: «Замок Траутсмандорф и сады Принцессы Сисси»

Прогулка по музею туризма и ботаническому саду. Этот тематический парк раскинулся на 12 га и включает в себя 4 маршрута, охватывающие флору почти всего мира - от лесов Северной Америки до Китая. Предусмотрен пикник на «пляже» (на территории парка).

Наблюдение заката с панорамной площадки «Бинокль Туна».

Ужин в традиционном тирольском трактире «Форст» и возвращение на автобусе в Больцано. (Парк открыт с начала апреля по середину ноября. В зимний период эта экскурсия может быть заменена на поездку в городок Брессаноне -Бриксен). 
День 5: «Альпийское плато Ренон и песчаные пирамиды».

Завтрак, переезд на фуникулере в местечко Обер-Боцен (1200 м)

Экскурсия на «ретро» поезде до поселка Колальбо, прогулка к озеру и посещение песчаных пирамид. Обед в трактире местечка Обербоцен. Возвращение в Больцано на фуникулере.

День 6: свободное время, отдых, шоппинг и подготовка к отправлению на поезде в Ниццу.

Подводя итоги, следует отметить, что организовав такой тур, появляется возможность удовлетворить потребности определенной группы населения и решить несколько культурно-социальных проблем.

Во-первых, отправляясь в путешествие на поезде, участники группы смогут посвятить больше времени себе самим и своему культурному развитию. Они смогут полюбоваться на пейзажи за окном, пересекая во время путешествия пять стран. Предполагается, что гид, который будет в команде сопровождения, будет давать краткие исторические экскурсы по мере прибытия в разные города (Брест, Варшава, Линц, Иннсбрукк и др.). Это позволит путешественникам еще ближе познакомиться с культурой и историей Европы.

Во-вторых, участники тура смогут познакомиться с людьми, близкими им по духу и интересам, поделиться историями жизни и своим опытом, завести новых друзей и испытать положительные эмоции. Известно, что пожилые люди в современном обществе часто страдают от одиночества. Участие в таком туре может, хотя бы частично, быть решением этой проблемы.

В-третьих, люди во время экскурсий по Больцано, Мерано, Ницце, Вене, не просто узнают много интересных исторических фактов об этих городах и их достопримечательностях. Они также узнают о своих далеких предшественниках, россиянах, которые путешествовали по этим же местам или жили там более века назад. Повышение уровня знаний и культуры представляется исключительно важным на фоне спада интереса к этим аспектам в современном мире, сфокусированном на потреблении и попкультуре.

В-четвертых, изучение историй наших соотечественников, живших за границей, поможет путешественникам лучше понять исконные ценности и приоритеты представителей нашей нации: благородство, вера в Бога, любовь к Родине, желание помочь ближнему, альтруизм и умение жить в сообществе. Это те качества, которых, безусловно не хватает людям в наше время и понимание этого, а также сознательное культивирование их, сделало бы наше общество более культурным и толерантным, а жизнь более приятной. 
В-пятых, сочетание культурно-познавательных мероприятий и легкой физической активности, таких как пешие прогулки и посещение термальных источников, предположительно хорошо скажутся на настроении участников и на их самочувствии, что немаловажно. Как представляется, впечатления от такого путешествия будут незабываемыми и рассказы о них привлекут новых участников.

К сожалению, в связи с пандемией и ограничениями, связанными с нею, вышеописанный проект не может быть осуществлен в этом году. Анализируя содержательный и мотивационный аспекты этого проекта, мы приходим к выводу о необходимости организовать данный тур в будущем.

\section{Список литературы}

1. Bellosi L., Giotto. Scala Group. - 2015. - 120 c.

2. Fleckinger A., Caracristi M., Ötzi, l'uomo venuto dal ghiaccio. Informazioni e curiosità sul celebre ritrovamento archeologico. Folio. - 2017. - 120 c.

3. Marabini Zoeggeler B., Talalai M., DIE RUSSISCHE KOLONIE IN MERAN. HUNDERT JAHRE RUSSISCHES HAUS „BORODINE“. РУCCKAЯ КОЛОНИЯ В МЕРАНО. К 100-ЛЕТИЮ РУССКОГО ДОМА ИМ. БОРОДИНОЙ. LA COLONIA RUSSA A MERANO. PER I CENT'ANNI DELLA CASA RUSSA "BORODINE". Associazione culturale Rus'. Edition Raetia, Bolzano - $1997-144 \mathrm{c}$.

4. Marabini Zoeggeler B., Talalai M., Русский Тироль. М.: Индрик - 2020 $-272 \mathrm{c}$.

5. https://www.altoadige.it/cultura-e-spettacoli/la-saga-di-re-art\%C3\%B9negli-affreschi-di-castel-roncolo-1.481436 (рис 1)

6. https://www.suedtirolerland.it/it/cultura-e-territorio/attrazioni/kurhaus-dimerano/ (рис 2)

7. https://upload.wikimedia.org/wikipedia/commons/b/b9/Meran_Villa_Boro dine_mit_St._Nikolaus.jpg (Рис. 3) 